\title{
Shuttle run performance induced injury rates of school boys on different sport surfaces
}

\author{
Aparup Konar ${ }^{1}$, Samiran Mondal ${ }^{2}$, Sridip Chatterjee ${ }^{3}$, Sourabh Lahiri ${ }^{4}$ \\ ${ }^{1}$ Director of Physical Instruction, Office of the Director of Physical Instruction, Sports Board, Jadavpur University, Kolkata-700032, \\ West Bengal, India \\ ${ }^{2}$ Associate Professor, Department of Physical Education, Visva Bharati University, Santiniketan - 731235, West Bengal, India \\ ${ }^{3}$ Assistant Professor, Department of Physical Education, Jadavpur University, Kolkata-700032, West Bengal, India \\ ${ }^{4}$ Sports Director \& HOD, Dept. of Physical Education, Hem Sheela Model School, J. N. Avenue, Durgapur -713214, West Bengal, India
}

\section{Email address:}

kaparup@gmail.com (A. Konar)

\section{To cite this article:}

Aparup Konar, Samiran Mondal, Sridip Chatterjee, Sourabh Lahiri. Shuttle Run Performance Induced Injury Rates of School Boys on Different Sport Surfaces. European Journal of Biophysics. Vol. 1, No. 4, 2013, pp. 33-36. doi: 10.11648/j.ejb.20130104.11

\begin{abstract}
Background: Sports surfaces not only play a significant role in influencing sports performance but also determining the risk of injury. The best running surface should be moderately soft \& smooth and widely used in a variety of games \& sports in schools. Aim: The aim of this study was to compare the shuttle run performance induced injury rates of school boys on five different sport surfaces in physical education classes. Method: Thirty six healthy school boys (Age: 14.06 \pm 0.41 years, Height: $1.60 \pm 0.08$ meters, Weight: $47.17 \pm 7.13$ kilograms, BMI: $18.59 \pm 3.21 \mathrm{~kg} / \mathrm{m}^{2}$ ) performed $4 \times 10 \mathrm{~m}$ shuttle run on five different sport surfaces (PVC, asphalt, turf, concrete bed \& soft clay) to evaluate speed-agility and subjective symptoms to determine injury rates. Result: The best average result of shuttle run performance was achieved on asphalt surface followed by PVC, soft clay, turf and concrete bed surface was found weak average result. In addition to safety, PVC surface provided greater security with reduced incidence of sports injuries and better performance of school boys. Conclusion: The impact of possible difference among the sport surfaces to obtain optimum shuttle run performance for school boys during competition, test and regular physical education activities under the condition of safety \& reduced risk of sports injuries.
\end{abstract}

Keywords: Shuttle Run Performance, Sport Surface, Schoolboy, Safety \& Injury Prevention

\section{Introduction}

Playing surfaces are the fundamental need for all sports facilities and widely used in a variety of games \& sports in schools. The surfaces on which athletes run on can play a vital role in determining how well they perform - and how likely they are to get injured. Different surface properties have different effects on the dynamics and mechanics of movement (Ferris et. al. 1999, Kerdok et. al. 2002). The properties of these surfaces not only influence sports performance but also affect injury rates (Girard et. al. 2007). Characteristics of the playing surfaces cannot be taken isolated when assessing injury risk (Dragoo \& Braun 2010). The influence of different surfaces should be used to prevent injury and provide security for school children when testing motor skills in this age group (Zivorad et. al. 2011). With increased participation in interscholastic sports
\& games by children, it is important for physical education teachers, coaches and health care providers to help reduce the risk of sports related injuries and enhance sports performance in this population. The best playing surface is essential elements for school children to conduct sports competitions as well as the activities during regular physical education classes. One of the important aspects in construction of sports surfaces is to improve athletic performance. (Baroud et. al. 1999, Daren et. al. 2003 \& Mc Mahon et al 1987).

\section{Methods}

Thirty six healthy school boys (Age: $14.06 \pm 0.41$ years, Height: $1.60 \pm 0.08$ meters, Weight: $47.17 \pm 7.13$ kilograms, BMI: $\quad 18.59 \pm 3.21 \mathrm{~kg} / \mathrm{m}^{2}$ ) randomly selected and participated in this study. None of the subjects was restrained by injury or fatigue. All the subjects regularly 
took part in their physical education classes at Hem Sheela Model School (HSMS), Durgapur, West Bengal, India. The running performance (speed-agility) was evaluated by $4 \times 10 \mathrm{~m}$ shuttle run test on five different sport surfaces. The assessment was conducted on outdoor asphalt, turf \& soft clay and indoor Poly Venial Chloride (PVC) \& concrete bed in standardized conditions and protocols for all the subjects. The subjective symptoms of injuries were measured by personal interview method from the subjects that they were suffering within one year such as joint pain, sprain, strain, muscle cramp etc. After warming up, the boys performed agility test on different days and all the measurements conducted in the morning school hours during regular physical education classes. In all the five tests they performed in the same shoes (white Cades). The PVC, asphalt and concrete bed surfaces were washed and dried. The turf was $3 \mathrm{~cm} \&$ dry and the soft clay surface also well dried to avoid susceptible of sports injuries and the possible changes in the direction of slip.

The descriptive statistics were calculated for measured each observed variables. The difference among the surface groups were analyzed using the ANOVA. The data are described as means \pm SD and significance level was set at $\mathrm{P}<0.05$ for all the statistical analysis.

\section{Results}

The description of mean values of the agility test of the boys on five different sport surfaces are presented in table 1.

Table 1: Comparison of 4x10m Shuttle Run Performance on Different Sport Surfaces of the study subjects $(n=36)$

\begin{tabular}{cccccc}
\hline $\begin{array}{c}\text { Sports } \\
\text { Surfaces }\end{array}$ & Mean & SD & Min & Max & $\begin{array}{c}\text { 95\% CI } \\
\text { for Mean }\end{array}$ \\
\hline Asphalt & 10.46 & 0.80 & 9.26 & 12.24 & 10.23 \\
PVC & 10.63 & 0.66 & 9.40 & 12.10 & 10.40 \\
Soft Clay & 10.67 & 0.59 & 9.74 & 11.78 & 10.38 \\
$\begin{array}{c}\text { Turf } \\
\text { Concrete }\end{array}$ & 10.69 & 0.72 & 9.54 & 12.15 & 10.41 \\
Bed & 10.72 & 0.62 & 9.72 & 12.64 & 10.49 \\
\hline
\end{tabular}

As per as running performance is concern, the best average result is achieved on the asphalt surface $(10.46 \mathrm{sec})$. The asphalt surface is the hardest and duration of the foot contact time (duration of the stance phase of the gait cycle) is shorter, which of course accelerate the runner's pace (Mc Mahon \& Greene 1979). The asphalt surface was found hard \& most fatiguing surface (D.Katkat et. al. 2009). Most of the time during physical education classes as well as afterschool free time are spent on asphalt surface as the most frequent type of surface in school facilities which is one of the most common causes of injury in classes
(Petrovic et. al. 1995). In addition to safety, PVC surface was found the next average result $(10.63 \mathrm{sec})$ which is not usual surface for physical education classes in school. The artificial surfaces demonstrated consistent or reduced variability with repeated use, which is speculated less problematic for the development of chronic/overuse injuries (Will H Gage et. al. 2012). Regarding the other two surfaces (soft clay \& turf) on which the result indicated slower performance $(10.67 \mathrm{sec} \& 10.69 \mathrm{sec})$ of the boys and the weakest result was obtained on the concrete bed surface $(10.72 \mathrm{sec})$. Runners slowed down dramatically on the softer surface for participants of the high school age (Markovic \& Visnjic 2008). On view of subjective symptoms of injuries, asphalt surface found maximum injury prone followed by concert bed surface. Though turf and soft clay surfaces were shown lower injury rate, but slower performance also. The PVC surface obtained minimum risk of injuries with optimum performance. Soft surface provide best result, in addition to greater security in physical education class (Radovanovic et. al. 1993). Running performance response to surface changes is related in factors such as body weight, connective tissue, anthropometry or dynamic segment alignment (Wissemann et. al. 2006).

Table 2: Analysis of variance of $4 x 10 m$ Shuttle Run Performance on Different Sport Surfaces $(n=36)$

\begin{tabular}{ccccccc}
\hline $\begin{array}{c}\text { Source of } \\
\text { Variance }\end{array}$ & $\begin{array}{c}\text { Sum of } \\
\text { Squares }\end{array}$ & df & $\begin{array}{c}\text { Mean } \\
\text { Square }\end{array}$ & F & Sig. \\
\hline $\begin{array}{c}\text { Between } \\
\text { Groups }\end{array}$ & 1.457 & 4 & 0.3643 & & \\
Within & 69.86 & 148 & 0.4720 & & \\
Groups & & & & & \\
\hline
\end{tabular}

*Insignificant at .05 level

F-value required to be significant at $4,148 \mathrm{df}=2.13$

Table 2 revealed that the obtained ' $F$ ' value of 0.7718 was found to be statistically insignificant difference at 0.05 , since this value was found lower than the tabulated value 2.13 at 4,148 df. $(p=.55)$.

\section{Discussion}

The best running surface should be moderately soft \& smooth. The hard surface is better for achieving the best results, although they are toughest on the body and increase the risk of injury. It produces high ground reaction forces which transmit shock through the body as the foot strikes the ground. In hard surface, maximum force, peak $\&$ mean pressure (Michael Eckl et. al. 2011 \& Girard et. al. 2010) were higher for the heel region and higher frictional coefficient that enhanced the speed but induce more frequent injuries. The potential mechanisms of surface properties affecting chronic injury risk could be based on 
increased peak moments or decreased impact attenuation properties of the surface. As the runner performed greater rate of acceleration, speed and torque, hyper extension with more muscle fatigue was found on hard surface. PVC surface produce low ground reaction force, lower frictional coefficient and easy on impact which is associated with reduced incidence of sports injuries and greater security. Concrete bed \& asphalt surfaces create the greatest impact on runner's legs and can lead to a variety of overuse injuries as well as lower back strain. Soft surfaces (PVC, soft clay \& turf) are easy on impact and foot is able to roll more smoothly resulting in more balanced force and pressure values. Lower frictional coefficient leads to longer sliding movement or longer contact time on the soft surface. Unlike indoor surfaces, outdoor surfaces are often uneven so the body gets a complete workout with its stabilizing musculature working harder and logically burning more calories and is the increased possibilities of injuries. Some studies investigated running on different surfaces on recreational samples (Leger \& Lambert, 1982; Pinnington, \& Dawson, 2001a; Kerdok et al., 2002) and samples consisting of athletes (Zampar et al., 1992; Pinnington \& Dawson, 2001b; Vitor Tessutti 2007), and very rarely on samples including school-age participants. Further research needs to be done to determine the impact of shuttle run performance on different sport surfaces including pvc induced injury rates of school children.

\section{Practical Applications}

The present study has suggested the effects of shuttle run performance on different sport surfaces under condition of safety of the school children. To better understand the causes behind why each sport surface has different impact on shuttle run performance induced injury rates and how pvc surface can be useful to minimized sports injuries of school boys. We hope this discussion gives a new way and inspires researchers to pursue additional work in this important area to better understand the relationship among sport surfaces, shuttle run performance $\&$ injury prevention.

\section{Conclusion}

The literature has shown that during sporting events the playing surface can influence the runner's risk of injury, and safety. In this study we compared five different sporting surfaces for assessing shuttle run performance changes induced injury rates of school boys in physical education classes. The PVC surface was shown to be the least variable and the asphalt surface was observed to have increased variability with use. The increased variability associated with negative consequences on chronic/overuse injuries. The impact of possible difference among the sport surfaces to obtain optimum shuttle run performance for school boys during competition, test and regular physical education activities under the condition of safety $\&$ reduced risk of sports injuries.

\section{What are the new findings?}

i. The present study subjectively observed different foot contact time, direction of slip, peak \& mean pressure, frictional coefficient, impact and ground reaction force for different sports surfaces in respect of the grip of sport shoes of the study subjects.

ii. Outdoor sport surfaces indicated more uneven than indoor surfaces.

iii. It has been found that, the subjects of the present study were from different socio-economic status, heriditical factors, nutritional status, educational status \& culture etc.

iv. The environmental condition of different tests days, if any, was beyond the control of the researcher.

v. There were no abnormal pathological and psychological difference among the subjects, the patho-psychological profile has not been measured and presumed that it was more or less same.

vi. Serial test conduction was not done due to feasibility of this study. The researcher had taken single test of every variable in the study group.

\section{How might it impact clinical practice in the near future?}

i. It might provide rich source of material for biomechanics personnel and related scientists.

ii. It would help to the health personnel who also may utilize the findings of the study in their endeavor.

iii. This study could stimulate discussion about the roles of the coaches who may utilize the reports of the study in their coaching programs and performance.

iv. It might help the sports and exercise persons to assert in the biomechanical analysis on sport surfaces and performance and thereby take care of it.

v. Physical education personnel might get new information about the field of biomechanics that may utilize the findings of the study in their pursuit.

\section{Acknowledgments}

The authors would like to acknowledge Dr. Rabindra N. Roy, founder president, HSMS, Durgapur and Professor, Drury University, USA. The authors would like to thank Hem Sheela Model School, Durgapur, West Bengal India, especially School management committee, trustee members, Principal, Vice Principals, for their cooperation \& help. The authors would also like to thank Mr. Amitesh Chakroborty and the entire Department of Physical Education, HSMS, Durgapur for their participation in our research studies. The authors would also like to acknowledge the Students, 
teachers \& supporting staff members for their assistance in this research work. The authors wish to express their sincere appreciation to the family members, who made significant contributions to the presented research outcomes.

\section{References}

[1] Baroud G, BM.Nigg D.Stefanyshyn (1999) Energy storage and return in sport surfaces. Sports Engin. 2:173-180

[2] D. Katkat, Y. Bulut, M. Demir, S. Akar (2009). Effects Of Different Sport Surfaces On Muscle Performance. Biology of Sport, Vol. 26 No3, 2009

[3] Daren J.S., B.M.Nigg (2003) Energy and Performance Aspects in Sport Surfaces. Third Symposium on Sports Surfaces (August), Calgary, Canada

[4] Dragoo, J.L. \& Braun, H.J. (2010). The effect of playing surface on injury rate: a review of the current literature. Sports Medicine, 40(11), 981-990.

[5] Ferris, D.P., Liang, K., \& Farley, C.T. (1999). Runners adjust leg stiffness for their first step on a new running surface. Journal of Biomechanics, 32, 787-794.

[6] Girard, O., Eicher, F., Fourcher, F., Micallef, J.P. \& Millet, G.P. (2007). Effects of the playing surface on plantar pressures and potential injuries in tennis. British Journal of Sports Medicine, 41, 733-738.

[7] Girard, O., Micallef, J.P. \& Millet, G.P. (2010). Effects of the playing surface on plantar pressures during the first serve in tennis. International Journal of Sports Physiology and Performance, 5(3), 384-393.

[8] Kerdok, A.E., Biewener, A.A., McMahon, T.A. Weyand, P.G. \& Herr, H. M. (2002). Energetics and mechanics of human running on surfaces of different stiffnesses. Journal of Applied Physiology, 92, 469-478.

[9] Leger, L., \& Lambert, J. (1982). A maximal multistage 20-m shuttle run test to predict VO2 max. European Journal of Applied Physiology and Occupational Physiology, 49, 1-12.

[10] Marković, Z., \& Višnjić, D. (2008). Influence of different surfaces on speed in high school girl student. Sports mont, (15), 361-366. Podgorica: Montenegro sport academy.

[11] McMahon T.A., G.Valiant, E.C.Frederick (1987) Groucho running. J.Appl.Physiol. 62:2326-2337

[12] McMahon, T.A. \& Greene, P.R. (1979). The influence of track compliance on running. Journal of Biomechanics, 12, 893-904.
[13] Michael Eckl, Philipp Kornfeind And Arnold Baca (2011). A comparison of plantar pressures between two different playing surfaces in tennis. vilas-boas, machado, kim, veloso (eds.), biomechanics in sports 29 portuguese journal of sport sciences 11 (suppl. 2), 2011

[14] Petrović, Z., Kebin, V., \& Ban, D. (1995). Categorization of school facilities for physical education. Fizička kultura, 46 (3-4), 249-254.

[15] Pinnington, H. C. \& Dawson, B. (2001b). Running economy of elite surf iron men and male runners, on soft dry beach sand and grass. European Journal of Applied Physiology, 86(1), 62-70.

[16] Pinnington, H. C. \& Dawson, B. (2001a). The energy cost of running on grass compared to soft dry beach sand. Journal of Science in Medicine and Sports, 4 (4), 416-430.

[17] Pinnington, H.C., Lloyd, D.G., Besier, T.F. \& Dawson, B.T. (2005). Kinematic and electromyography analysis of submaximal differences running on a firm surface compared with soft, dry sand. European Journal of Applied Physiology, 94, 242-253.

[18] Radovanović, Đ., Arunović, D., Madić, B., \& Visnjić, D. (1993). Attitudes of secondary school students in Serbia according to physical education teachers characteristics. Fizička kultura, (1-2), 10-13.

[19] Tessutti, V., Pereira, C., Trombini, F., Onodera, A., \& Sacco, I. (2007). Plantar pressure distribution during running in different surfaces. H.-J. Menzel, M. H. Chagas (Eds), XXV ISBS Symposium 2007 (p. 243), Ouro Preto - Brazil.

[20] Will H Gage, Eric M. yons, Dmitry Verniba (2012). Contribution of Field Playing Surface Type and Quality to Potential Acute and Chronic Injury Rates. Article submitted to the STA for winter issue of the Sports Turf Manager Scientific Publication is to be submitted by December 2012.

[21] Wissemann, I., Potthast, W., \& Brüggemann, G. P. (2006). Changes in EMG signals while running on different surfaces. In H. Schwameder, G. Strutzenberger, V. Fastenbauer, S. Lindinger, E. Müller (Eds), XXIV ISBS Symposium 2006, suppl 4 (pp 1-4) Salzburg - Austria.

[22] Zampar, P., Perini, R., Orizio, C., Sacher, M., \& Ferretti, G. (1992). The energy cost of walking or running on sand. European Journal of Applied Physiology and Occupational Physiology, 65(2), 183-187.

[23] Živorad Marković1, Aleksandar Ignjatović1, Dragan Radovanović2, Dragoljub Višnjić3 (2011). The running performance of schoolchildren On different surfaces. Physical Education and Sport Vol. 9, No 2, pp. 213 - 218 UDC 796.4:053.5. 